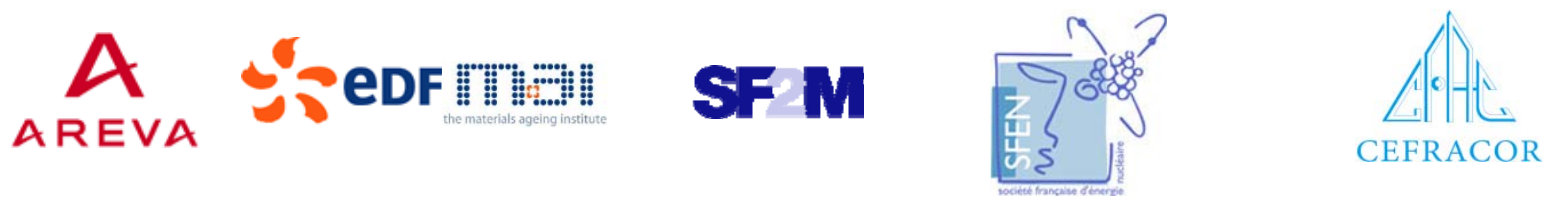

\section{MIN口S}

Centre of Excellence for Nuclear Materials

\section{Workshop}

Materials Innovation for Nuclear Optimized Systems
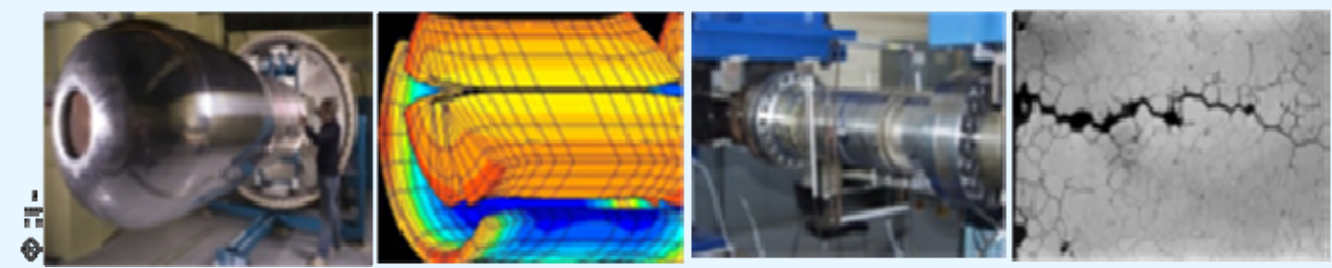

December 5-7, 2012, CEA - INSTN Saclay, France

\section{Hélène BURLET \\ CEA (France)}

Mechanical and Thermal Resistance of Multi-Material Components for ITER

Workshop organized by:

Christophe GALLÉ, CEA/MINOS, Saclay - christophe.galle@cea.fr Constantin MEIS, CEA/INSTN, Saclay - constantin.meis@cea.fr 


\title{
Mechanical and Thermal Resistance of Multi-Material Components for ITER
}

\author{
Hélène BURLET ${ }^{1}$ \\ ${ }^{1}$ CEA-DEN-DRT, Laboratoires d'Innovation pour les Technologies des Energies, LITEN (Grenoble, France)
}

The First Wall panels for ITER are complex parts composed of stainless steel, copper and beryllium [1]. These materials are joined using diffusion bonding technique. The stainless steel is a commonly used in nuclear reactors $316 \mathrm{LN}$ material and acts as a structural material. The copper alloy is a CuCrZr material which acts as a heat sink. The beryllium consisting in tiles and layer is used as the protective plasma facing material.

The fabrication of these panels is performed through 2 main steps. The first step consists in welding all together a bi-metallic support structure made from a thick CuCrZr plate embedded with 316LN tubes and bonded to a thick 316LN backing plate with cooling channels. The bonding is performed in a HIP (Hot Isostatic Pressure) facility. The second step is performed at a lower temperature and aims at simultaneously welding by HIP Be onto $\mathrm{CuCrZr}$ and ageing the $\mathrm{CuCrZr}$ heat sink to obtain the correct mechanical resistance of this alloy reinforced by precipitates.

The various joints 316LN/316LN, 316LN/CuCrZr, and CuCrZr/Be are then characterized [2] from a microstructural point of view and by mechanical tests. It is quite hard to characterize the strength of a diffusion bonded joints. Standard tests may be used for homogeneous joints whereas specific tests have been developed to characterize the heterogeneous bonds. To optimize the bond, we performed mainly impact and tensile bimaterial tests (Fig 1). Once the manufacture parameters have been optimized, advanced mechanical tests are performed based on Bimetallic CT specimens, axisymmetric notched specimens, $4 \mathrm{P}$ bending specimens. Numerical simulations are required to analyse the mechanical response. In order to characterize the fatigue resistance of the joints, specific mock-ups have been designed by the European Fusion Development Agreement - EFDA - team (Fig 2).

Results of heat flux testing will be reviewed for the various joints. The assembly of heterogeneous materials by HIPping is very complex. It may be used for various applications appart ITER FW panels such as test blanket module and divertor. It is also envisaged in PWR fission reactors, for instance to join 316 stainless steel onto 16MND5.

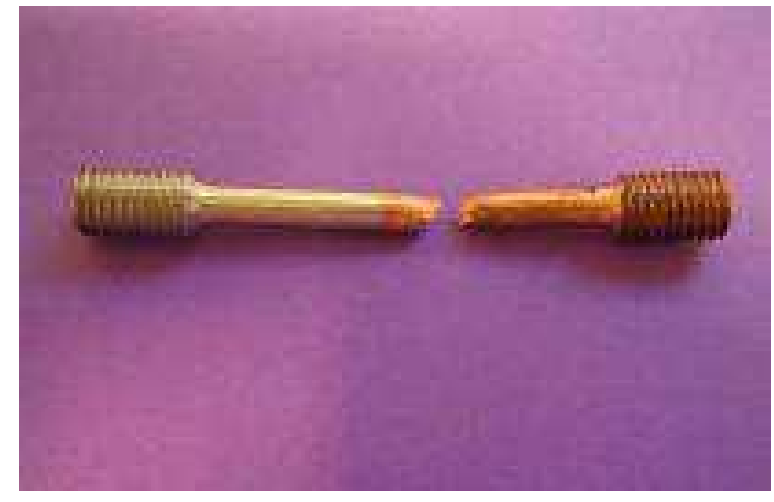

Fig. 1: Tensile tests specimens CuCrZr/316LN.

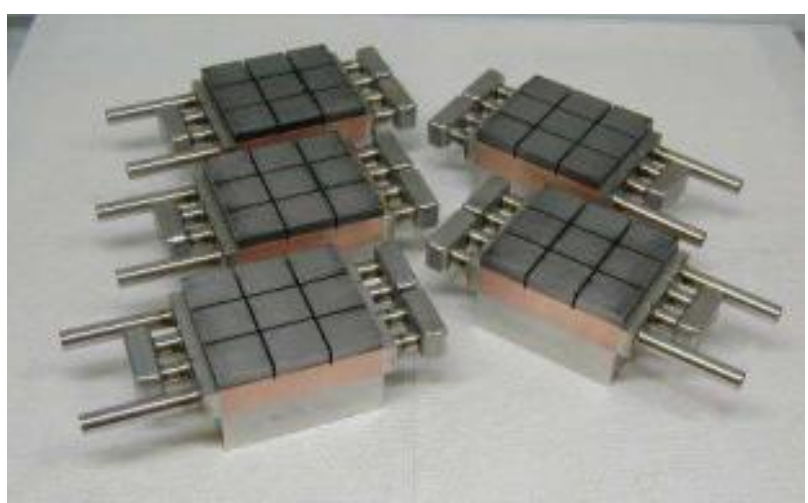

Fig. 2 : Mock-ups for high heat flux tests.

This is an Open Access article distributed under the terms of the Creative Commons Attribution License 2.0, which permits unrestricted use, distribution, and reproduction in any medium, provided the original work is properly cited. 


\section{References}

[1] Boudot, C., Boireau, B., Cottin, A., Lorenzetto, P., Bucci, P., Gillia, O., Manufacture of a shield prototype for primary wall modules. Fusion Engineering and design, Volume 83, Issues 7-9, December 2008, pp. 1294-1299.

[2] Gillia, O., Briottet, L., Chu, I., Lemoine, P., Rigal, E., Peacock, A., Characterization of CuCrZr and CuCrZr/SS joint strength for different blanket components manufacturing conditions. Journal of Nuclear Materials, Volumes 386-388, 30 April 2009, pp. 830-833. 
DE LA RECHERCHE À L'INDUSTRIE
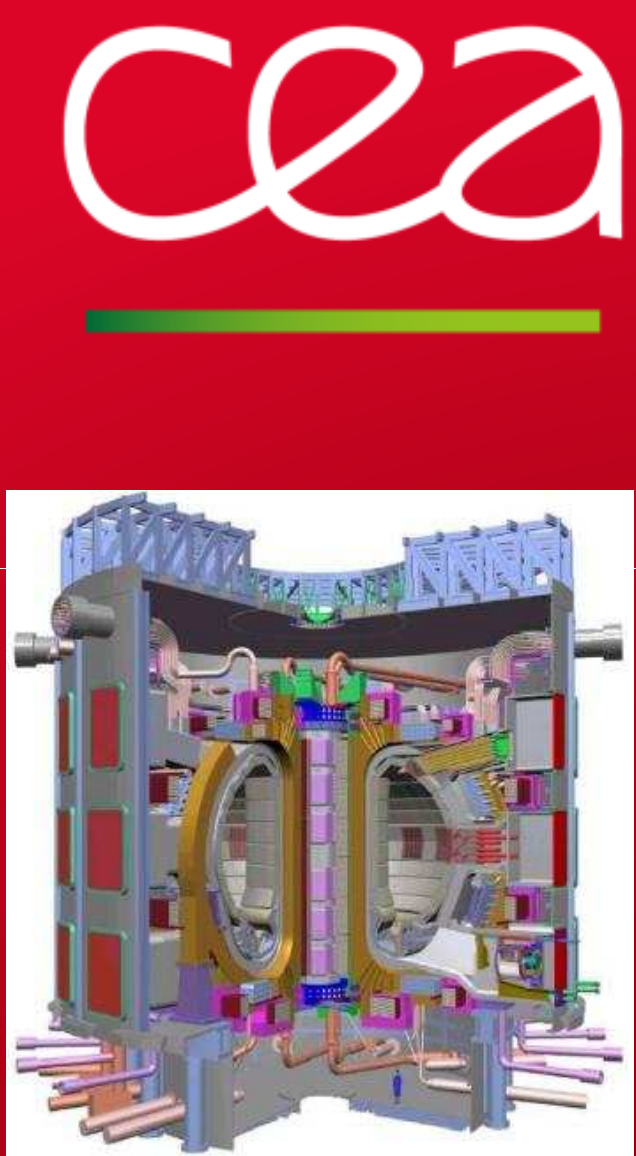

www.cea.fr
MECHANICAL AND

THERMAL RESISTANCE OF

MULTI-MATERIAL COMPONENTS FOR ITER

MINOS workshop : Materials innovation for Nuclear Optimized Systems - Helene Burlet

DECEMBER, 5-7, 2012

Iiten 


\section{Cea FIRST WALL PANELS}

E Complex components with multi materials :

Structure : stainless steel 316LN "Iter grade"

Heat sink : Copper alloy reinforced with precipitates

Armor : beryllium tiles

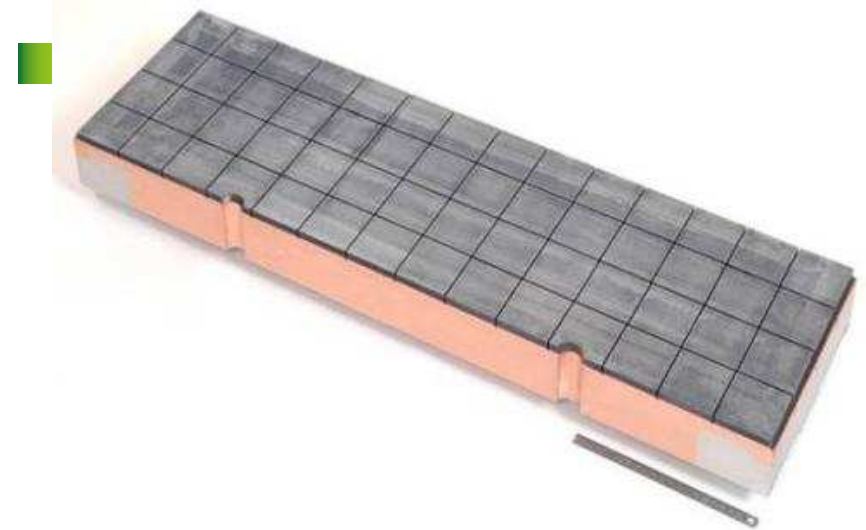

Initial design

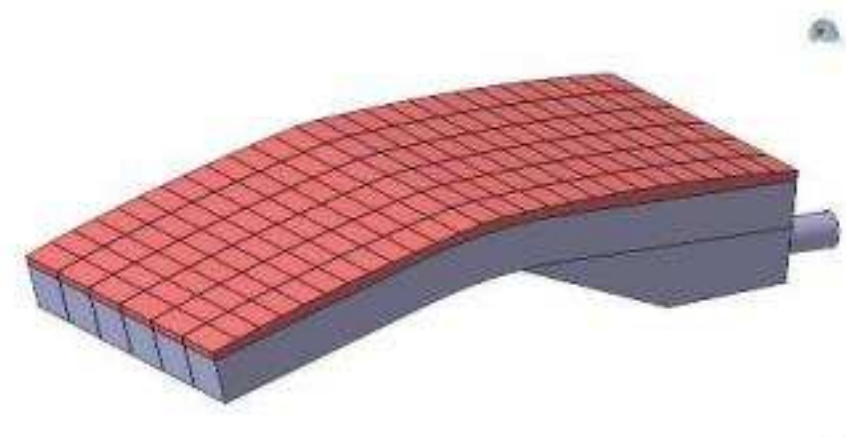

New design 
PROCESS ROUTES FOR THE FIRST WALL PANELS 


\section{CQZ HIPPED FIRST WALL PANELS}

\section{Hot Isostatic Pressing : reference route}

n HIP : solid state bonding under high Temperature \& high Pressure

- Multi steps route

- SS/SS/Cu : one-step HIP cycle : $1040^{\circ} \mathrm{C} / 2 \mathrm{~h}$ - $140 \mathrm{MPa}$

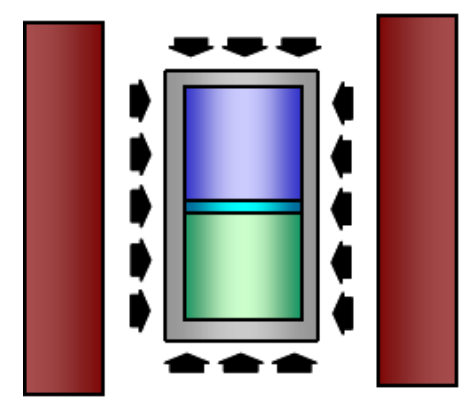

- Solutionning and heat treatment : $9800^{\circ} \mathrm{C} / 1 \mathrm{~h}$ and $60^{\circ} \mathrm{C} / \mathrm{min}$ between $980^{\circ} \mathrm{C}$ and $480^{\circ} \mathrm{C}$

- HIP cycle applied for Be/CuCrZr : 580 C/2h - $140 \mathrm{MPa}$

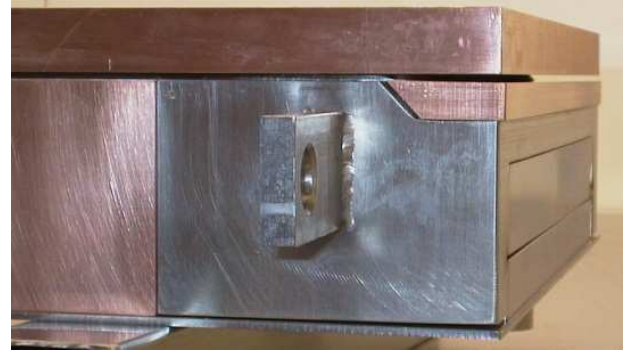

Iiten

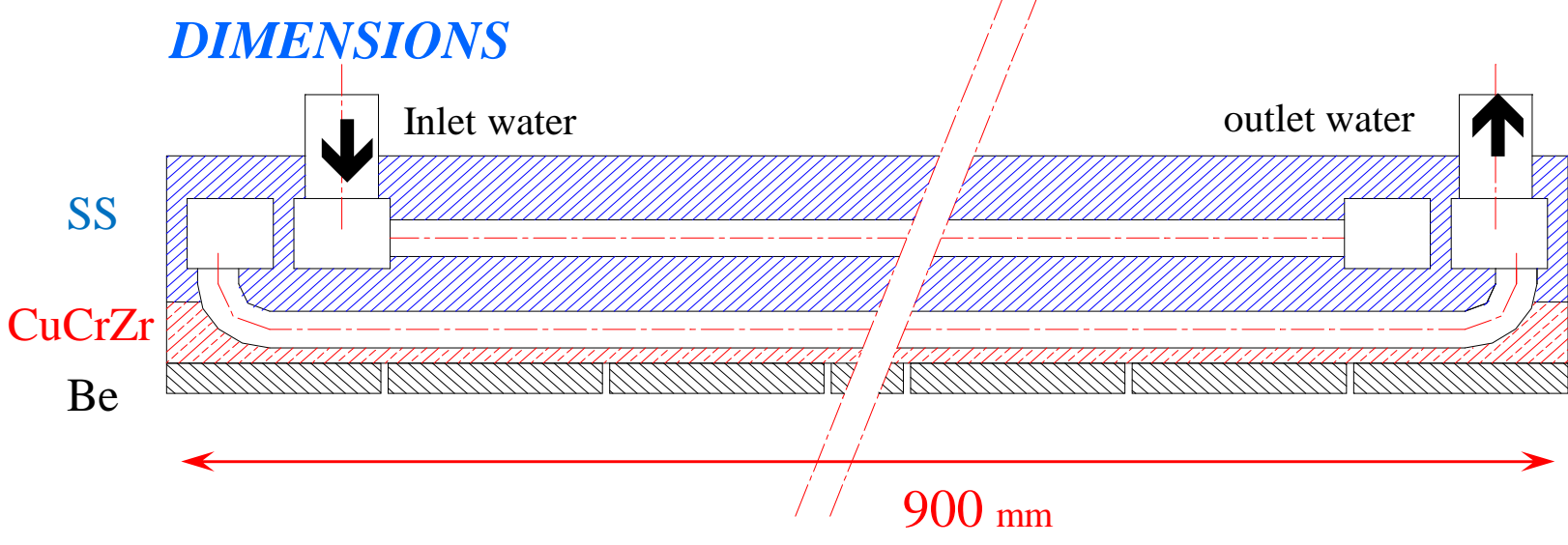

MINOS Workshop | December 5-7 2012| PAGE 4 


\section{CQح HIPPED FIRST WALL PANELS}

\section{SS/SS/CuCrZr bonding}

- Development of specific non destructive US control on calibrated holes

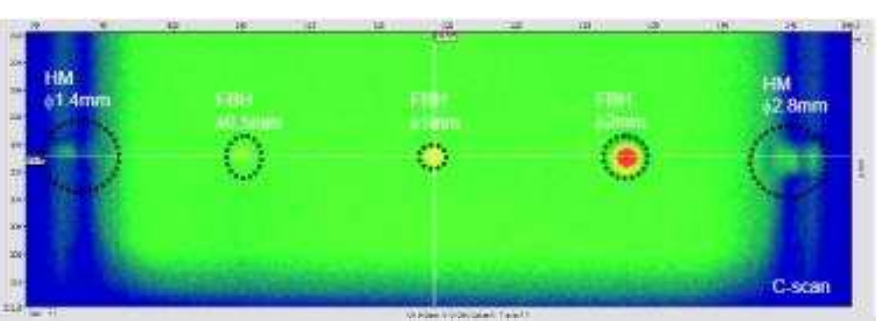

- Ultrasonic Control of the FWP

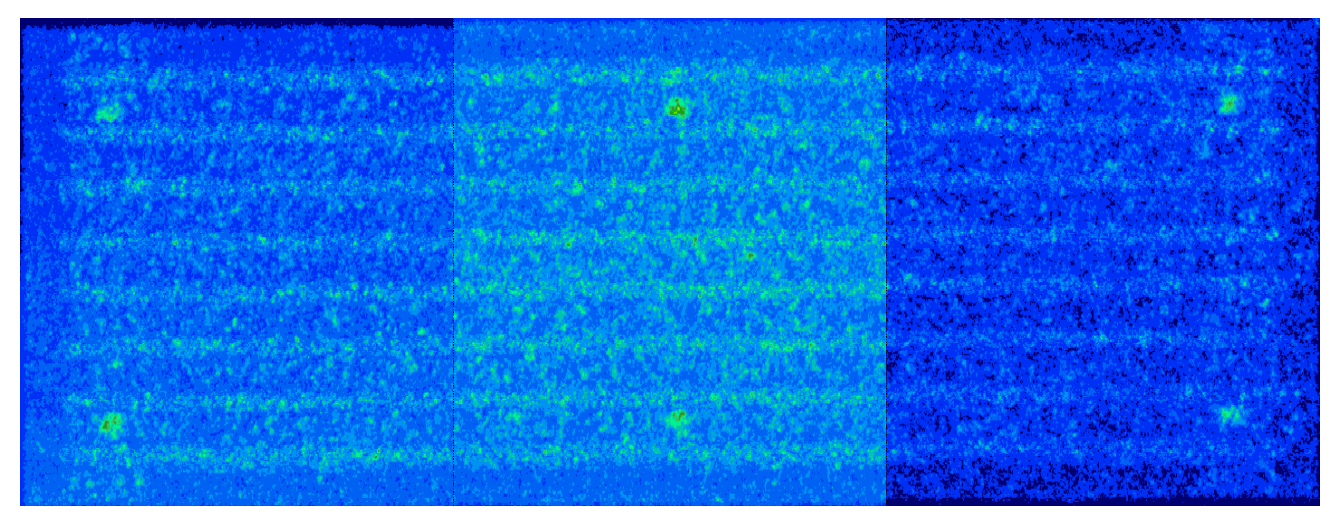

$\rightarrow \quad$ No defect has been detected in $\mathrm{Cu} / \mathrm{SS}$ interfaces

$\rightarrow 6$ little spots : modification in the properties of $\mathrm{CuCrZr}$ 


\section{CQح HIPPED FIRST WALL PANELS}

Beryllium tiles bonding

- Need for interlayers

$\checkmark$ Between Cu and Be to prevent diffusion and precipitation of brittle phases

$\checkmark$ Between tiles to control the distance

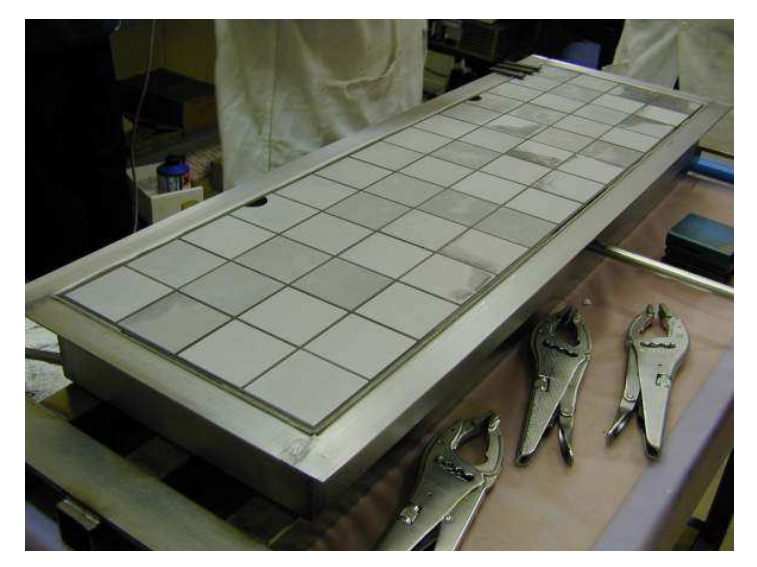

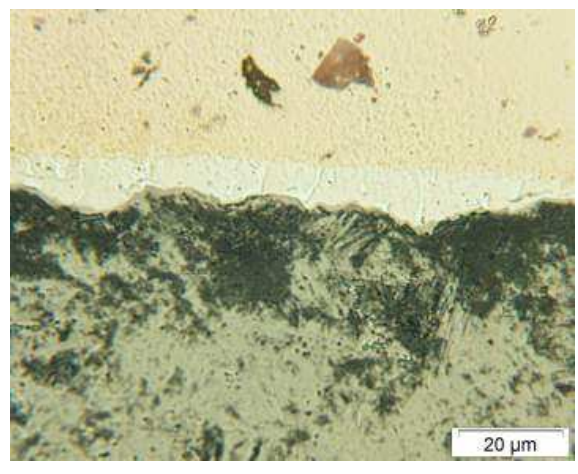

Example of interlayers between $\mathrm{Cu}$ and $\mathrm{Be}$

Graphite interlayer

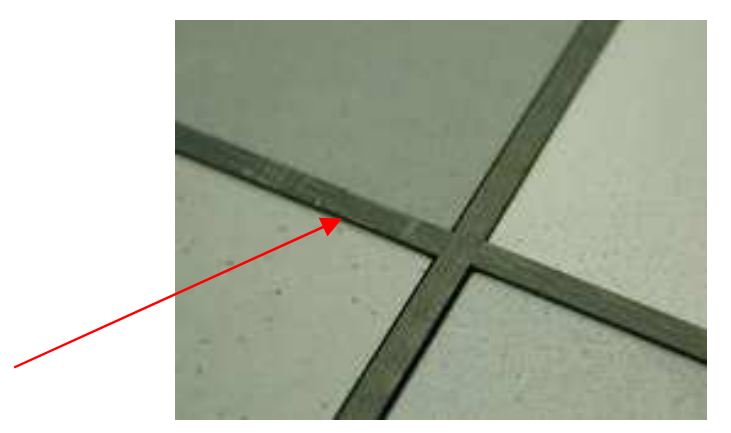


CHARACTERIZATION OF THE VARIOUS JOINTS AND MATERIALS 


\section{Cea MICROSTRUCTURAL EXAMINATIONS}

\section{SS/SS/CUCrZr JOINT OBSERVATION}

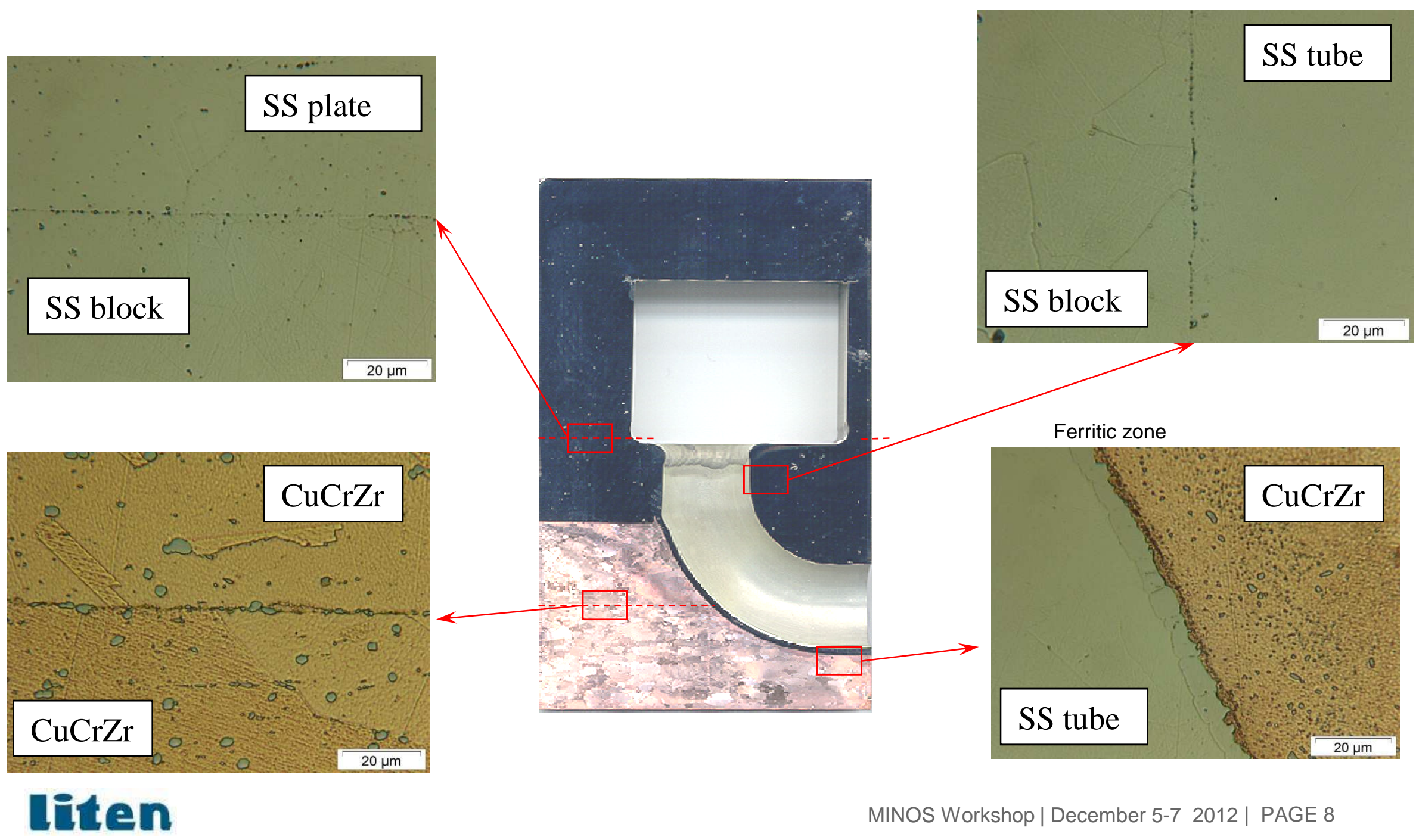




\section{Cea MECHANICAL CHARACTERISATION}

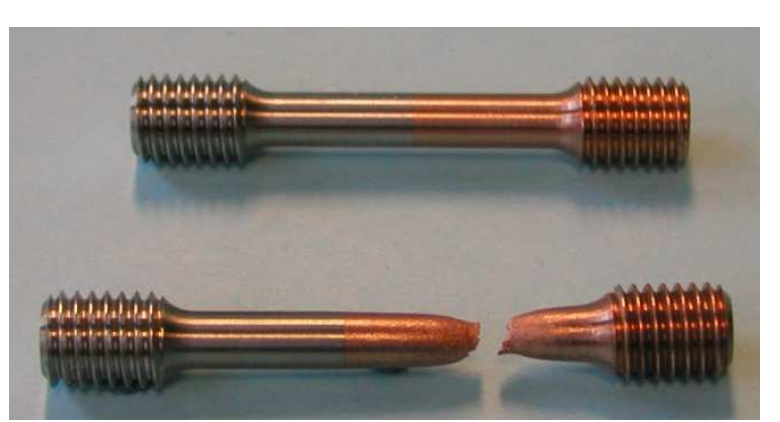

First tests :

$\checkmark$ Tensile tests

$\checkmark$ Impact Toughness tests with $U$ shape notches

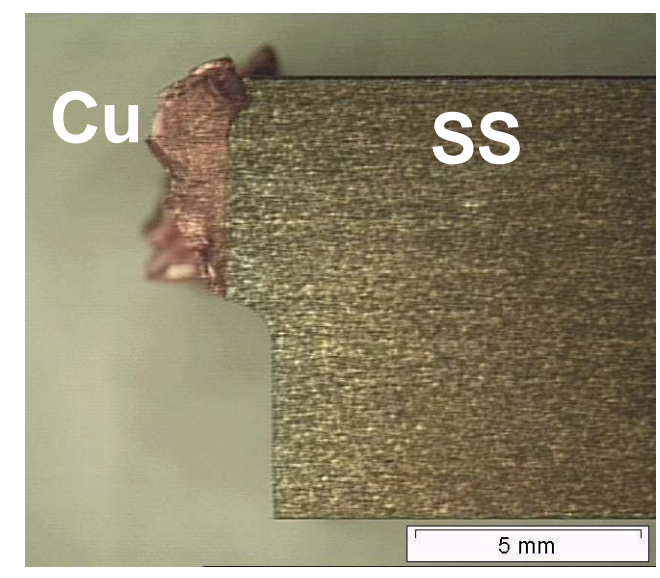

First criterion : the joint must not be the weakest zone

Further tests are requested to characterize the mechanical resistance of the joint 


\section{Cea MECHANICAL CHARACTERISATION}

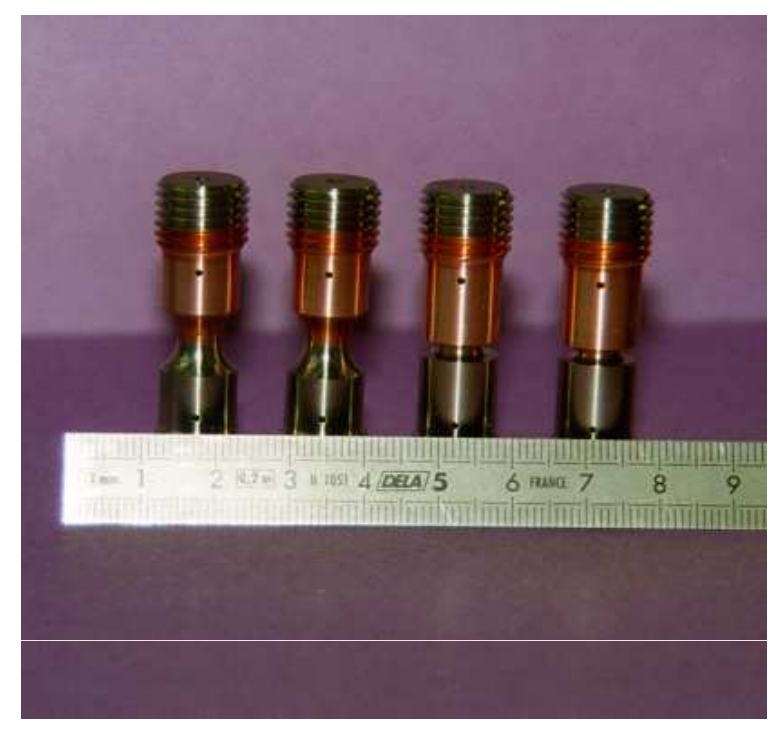

Notched specimens
Mechanical analysis of heterogeneous joints

$\checkmark \quad$ Tests

$\checkmark$ Examinations

$\checkmark$ Modelling

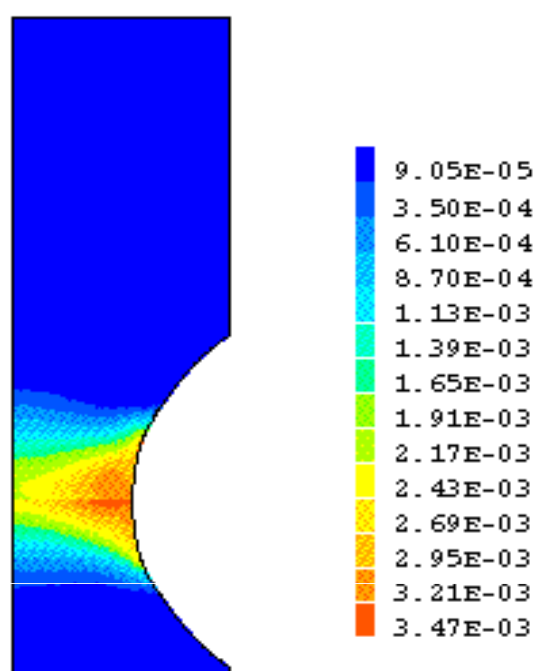

\section{Iiten}

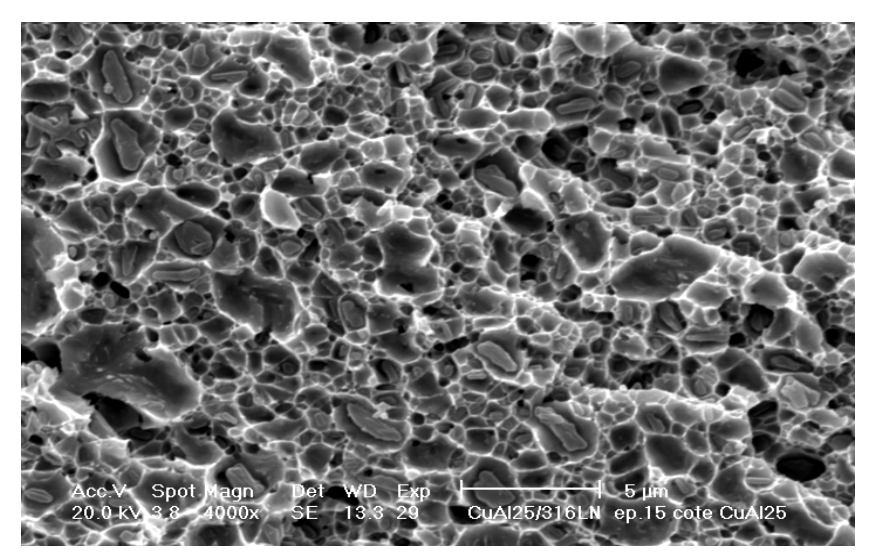

Fracture surface

Plastic deformation map 


\section{Cla TESTS AT ROOM TEMPERATURE}

Determination of mechanical laws of the materials of the ZAD (Zone affected by the Diffusion)

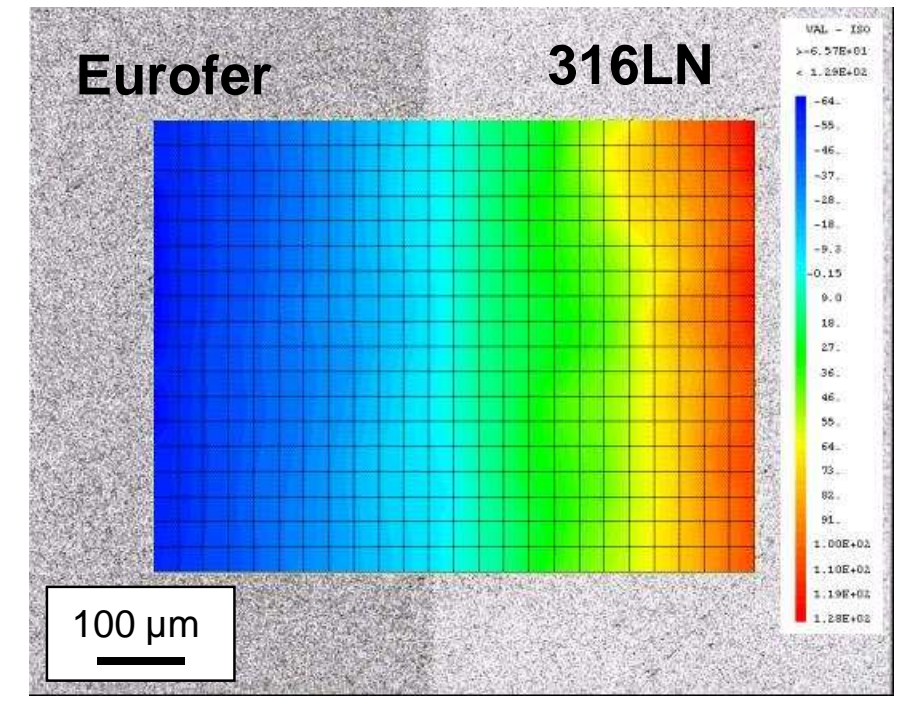

Displacement measurement on a SEM platform
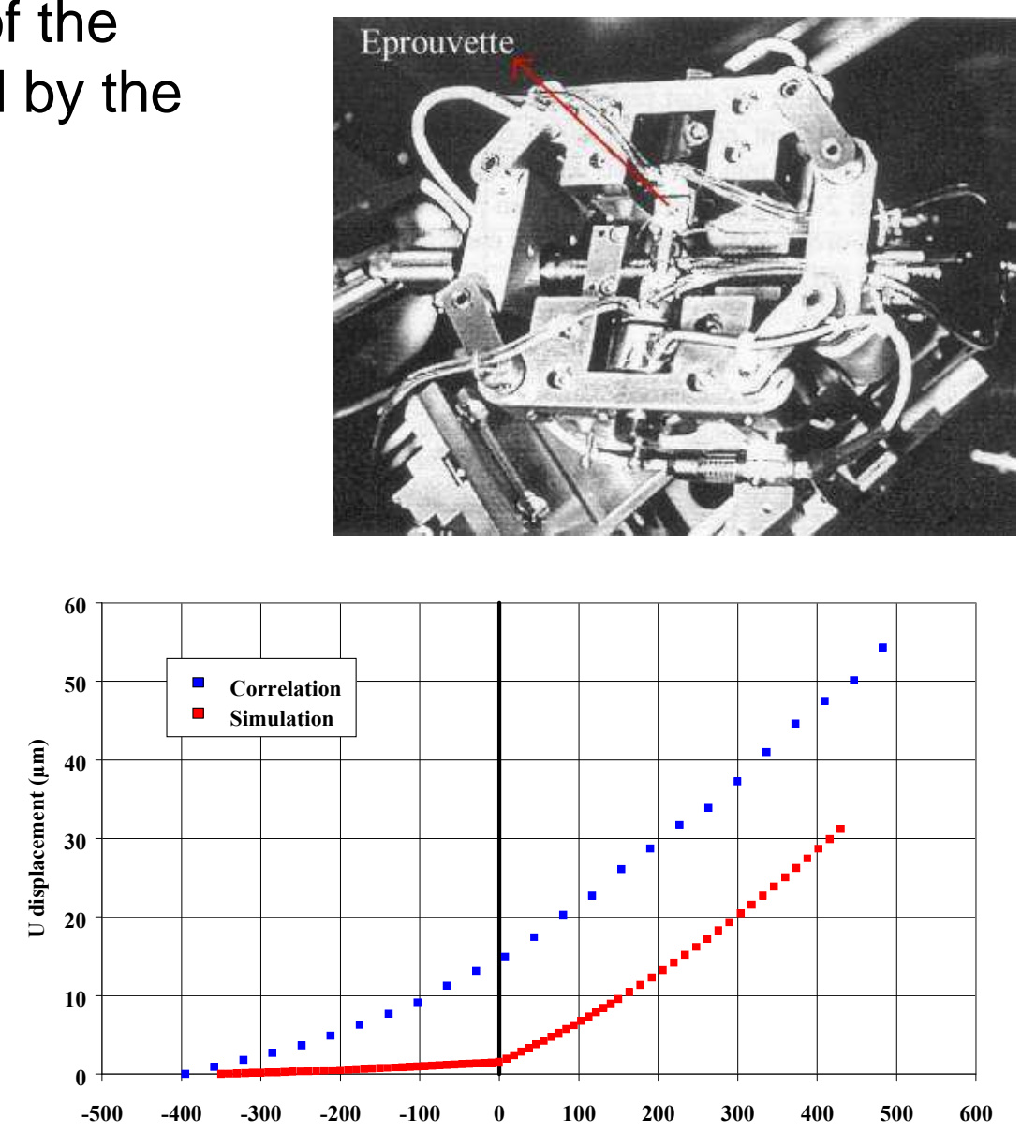

Comparison of the simulation results and the correlation maps

\section{Iiten}




\section{Cea MECHANICAL CHARACTERISATION}

CT tests on bimaterial side grooves specimens
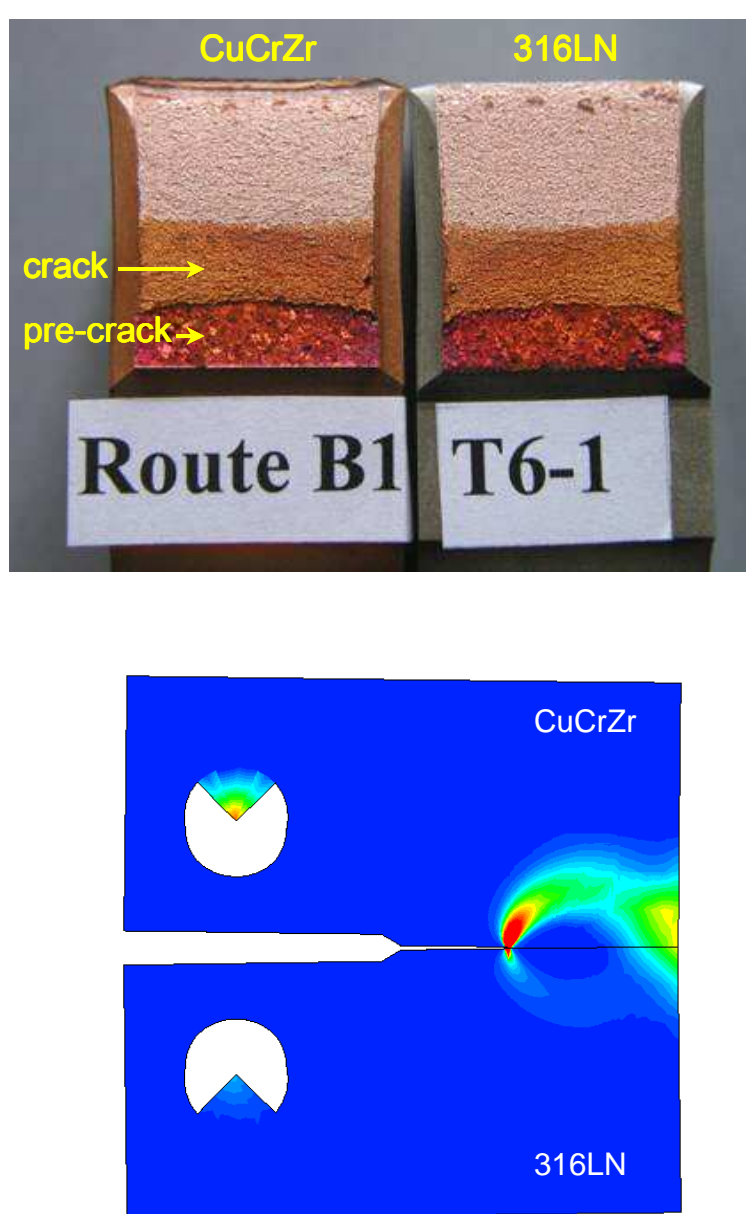

\section{Stable crack propagation}

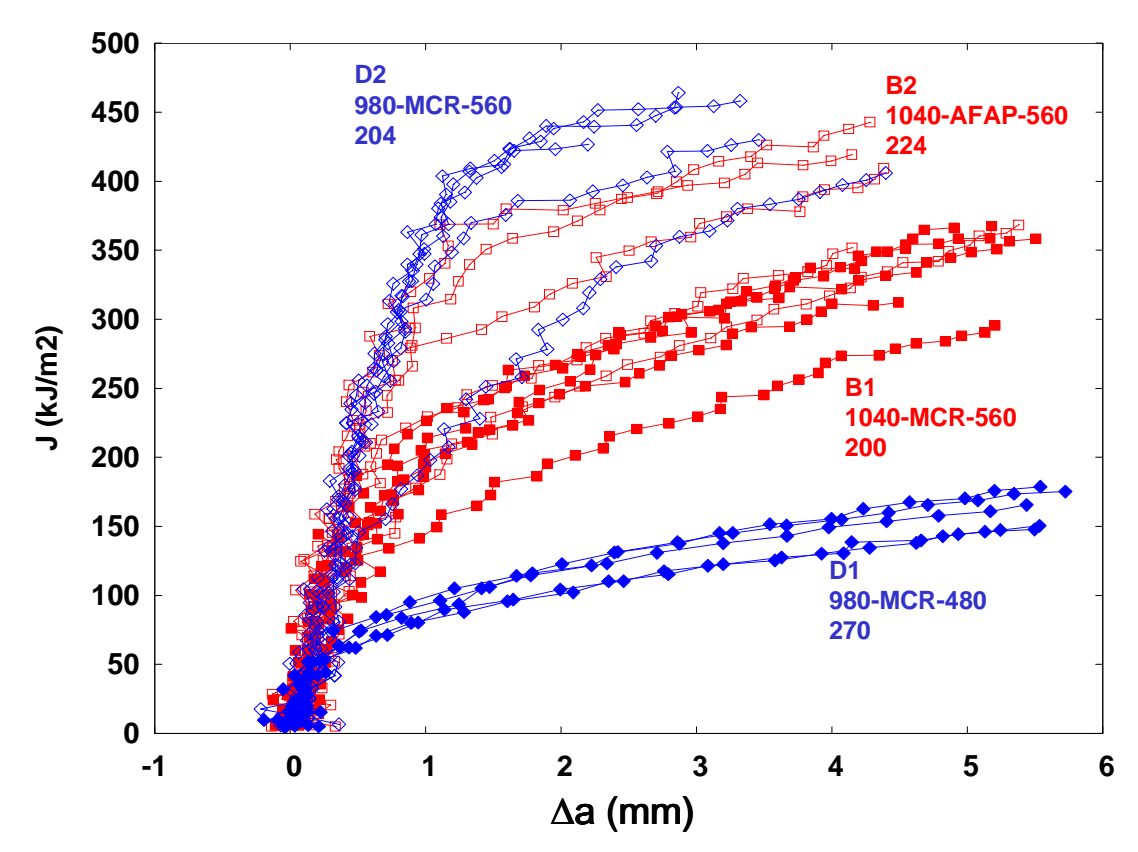

CT tests give usefull indications on the influence of the process route 

JOINTS

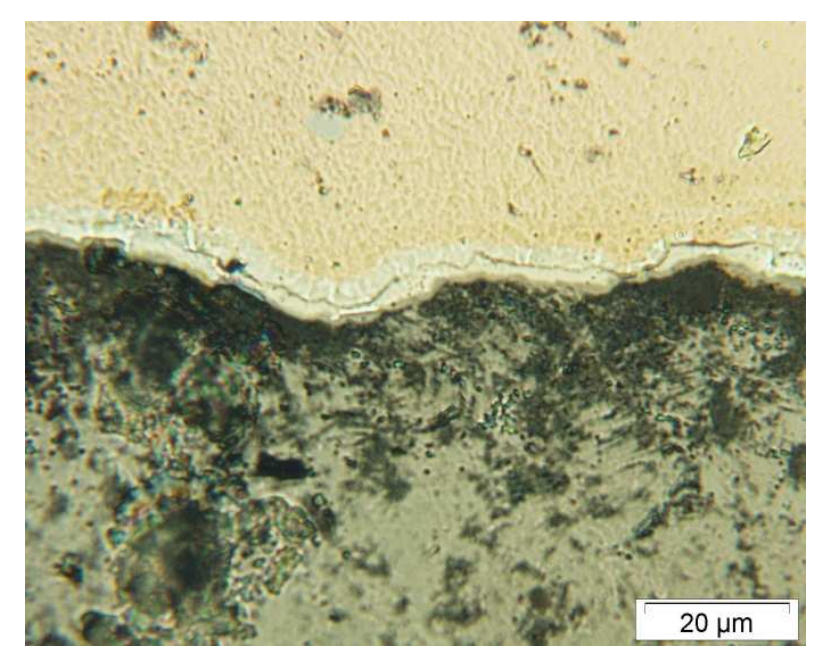

$\rightarrow$ US reveals no indications for this specimen

$\rightarrow$ No cracks nor residual porosities

Three different zones

$\rightarrow$ alignment of precipitates (initial interface)

$\rightarrow$ Much cleaner zone

$\rightarrow$ No diffusion observed
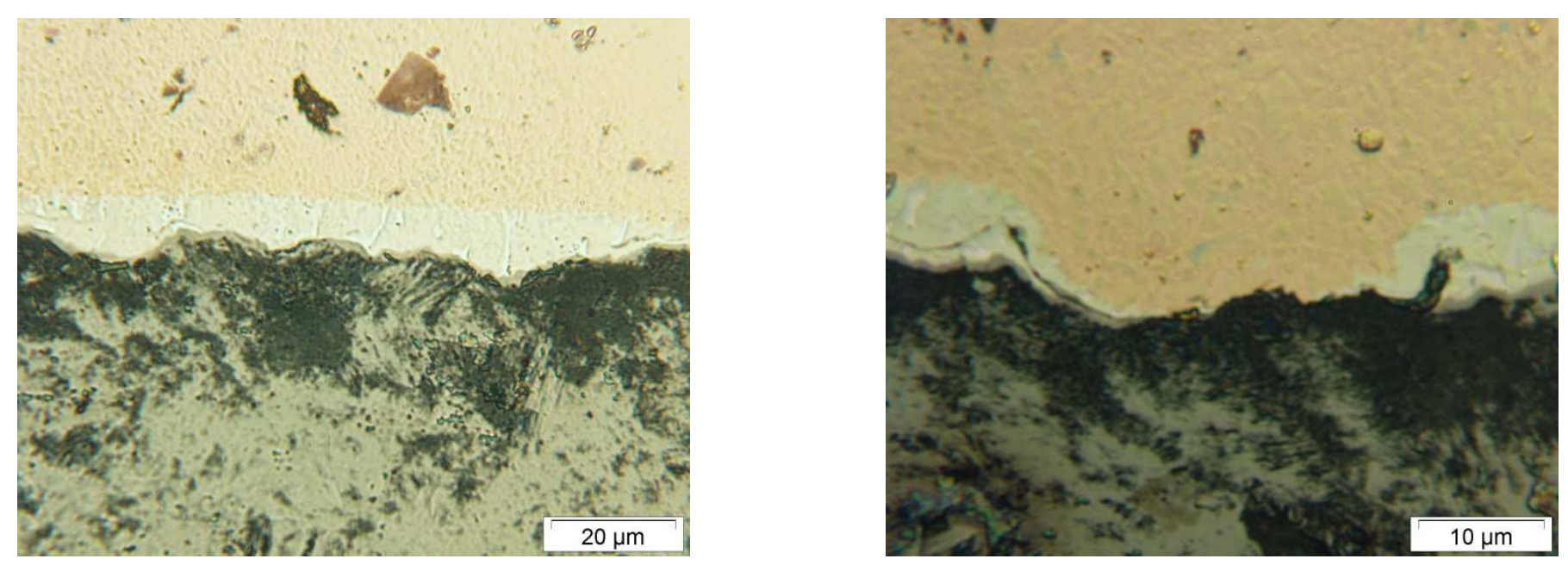
HEAT FLUX TESTING OF MOCK-UPS 


\section{CeA MOCK-UPS : DIFFERENT DESIGN}
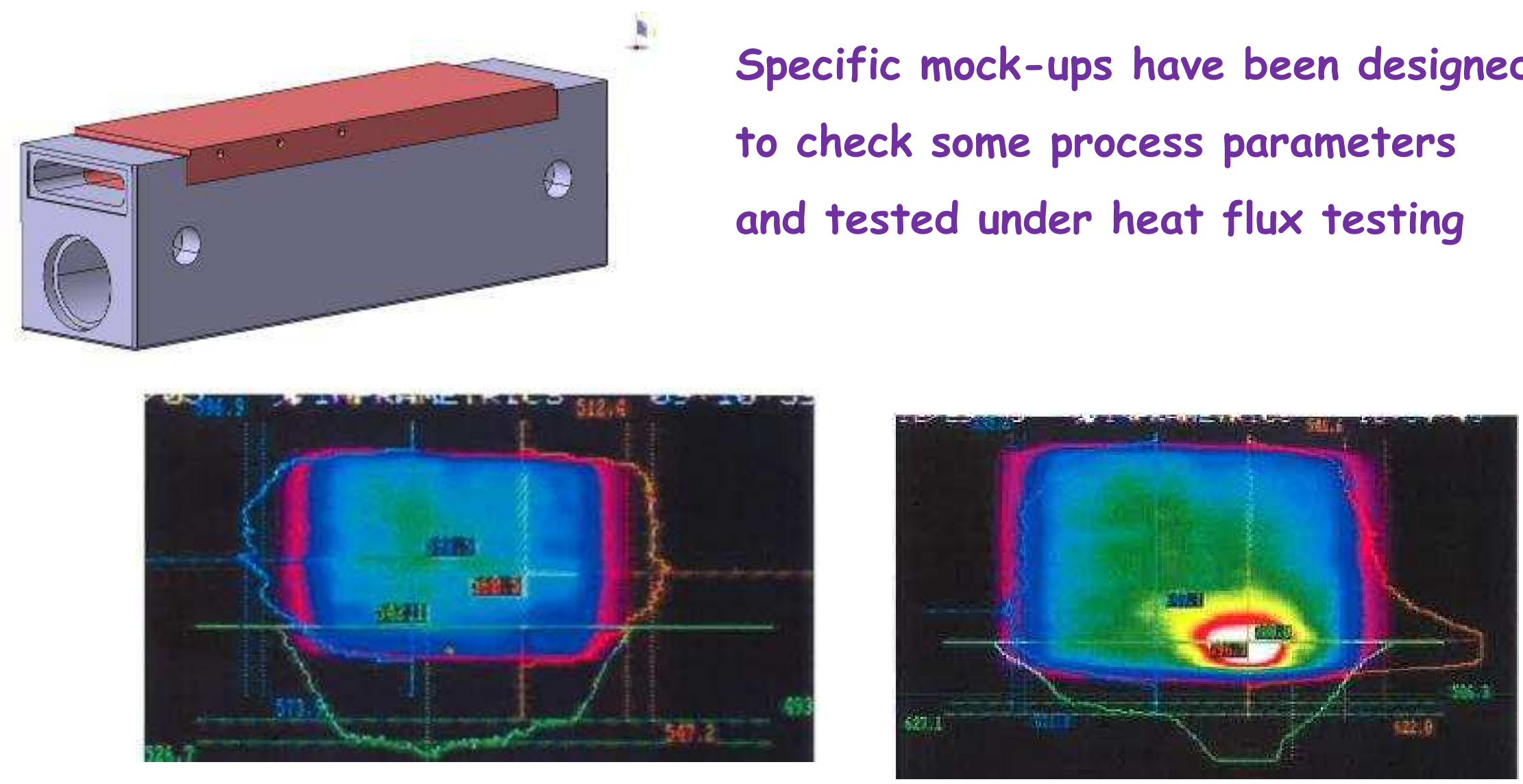

Hot point detected after 267 cycles at $7 \mathrm{MW} / \mathrm{m}^{2}$ 


\section{Ceح MOCK-UPS FOR THERMAL TESTS REQUIRED BY EFDA}
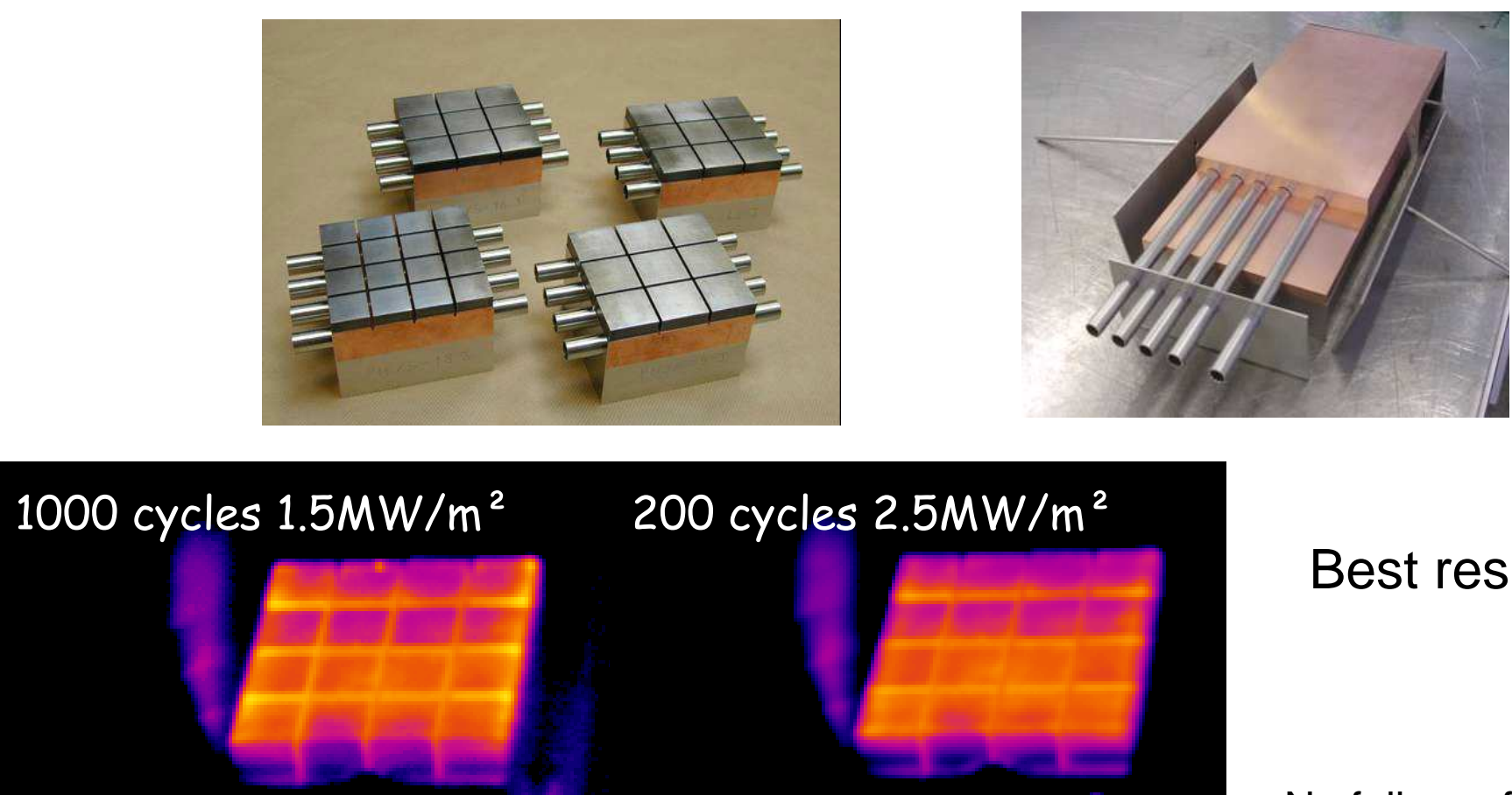

T surface $\mathrm{Be} \sim 270^{\circ} \mathrm{C} \quad \mathrm{T}$ surface $\mathrm{Be} \sim 390^{\circ} \mathrm{C}$

200 cycles $3 \mathrm{MW} / \mathrm{m}^{2}$

200 cycles $3.25 \mathrm{MW} / \mathrm{m}^{2}$
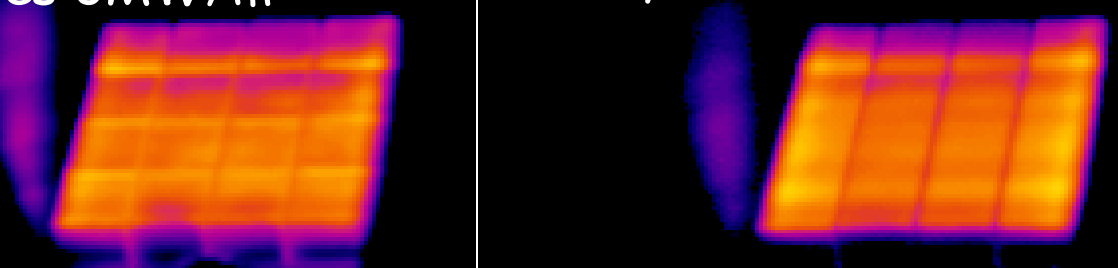

No failure of $\mathrm{Be} / \mathrm{Cu}$ joint is observed but the test stop after 200 cycles at $3.25 \mathrm{MW} / \mathrm{m}^{2}$ because Be surface temperature reached $650^{\circ} \mathrm{C}$

T surface $\mathrm{Be} \sim 510^{\circ} \mathrm{C}$

T surface $\mathrm{Be} \sim 650^{\circ} \mathrm{C}$ 


\section{cea concLusions}

- HIP technique is well adapted to develop complex multimaterial parts

- HIP is foreseen for the Test Blanket Module TBM

- HIP is now well controlled

specific US controls have been developed

Hipped SS/SS developed for Cabri experimental reactor

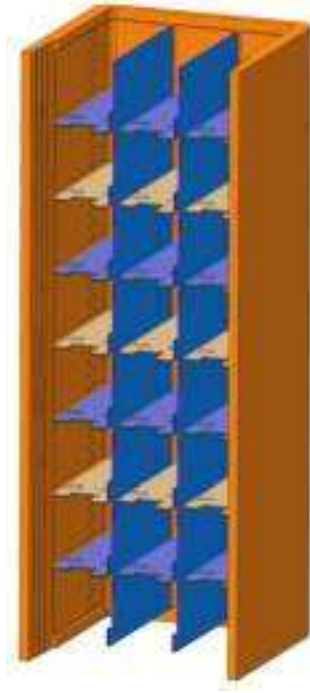
have been accepted by $B C C N$

* Further applications

316LN/16MND5 joints for PWR

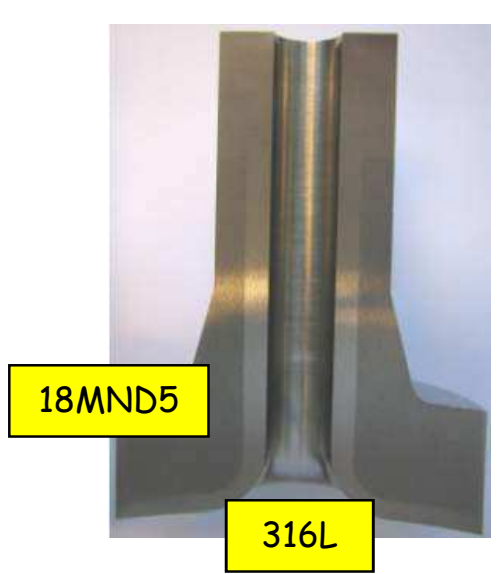




\section{cea}

\section{$\underline{\text { Acknowledgement }}$}

All this work has been done under the strong support of the European Community (EURATOM) and of EFDA association.

\section{EURATOM}

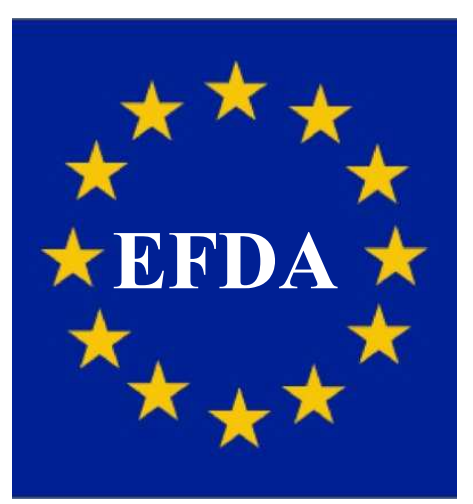


